\title{
Duodenal Diverticulum Causing Xanthogranulomatous Pyelonephritis with Multiorgan Involvement: First Case Report
}

\author{
Julian E. Losanoff ${ }^{a} \quad$ Trevor W. Reichman $^{b}$ Gary D. Steinberg ${ }^{b} \quad$ J. Michael Millis ${ }^{b}$ \\ Departments of Surgery, ${ }^{a}$ Wayne State University, Detroit, Mich., and ${ }^{b}$ University of Chicago, Chicago, Ill., USA
}

Dear Sir,

Xanthogranulomatous pyelonephritis (XGP) is a chronic destructive inflammatory process which very rarely originates from the digestive tract. A previously healthy 40-year-old female patient presented with an asymptomatic abdominal mass. Physical examination revealed a $10 \times 15 \mathrm{~cm}$ tumor in the right hypochondrium which was non-tender and fixed to the liver. All laboratory tests were within normal limits. An abdominal CT scan showed a solitary multiloculated mass involving the proximal kidney and right hepatic lobe (fig. 1).

Abdominal exploration revealed a $14 \times 12 \mathrm{~cm}$ firm mass infiltrating the proximal third of kidney, duodenum, and Couinaud segment VI of the liver. Dissection posterior to D3 found a $1.5 \times 0.8 \mathrm{~cm}$ duodenal diverticulum which widely communicated with the necrotic center of the tumor. A radical nephrectomy, liver segmentectomy VI, and excision of the diverticulum produced a whole specimen which was sent for pathology. The resulting defect of the duodenal wall was anatomically restored in two layers. Pathology revealed XGP with extensive infiltration of the liver parenchyma and no malignancy. The patient was last seen 4 months after surgery and had no complaints; all laboratory tests remained within normal limits.
$\mathrm{XGP}$ is a rarely described chronic inflammatory process characterized by partial or full destruction of the kidney and replacement by granulomatous tissue containing foamy, lipid-laden macrophages
[1]. The condition's pathogenesis is possibly related to urinary obstruction, lowgrade infection, abnormal lipid metabolism, arterial, venous, or lymphatic obstruction, altered immunity, hemorrhage,

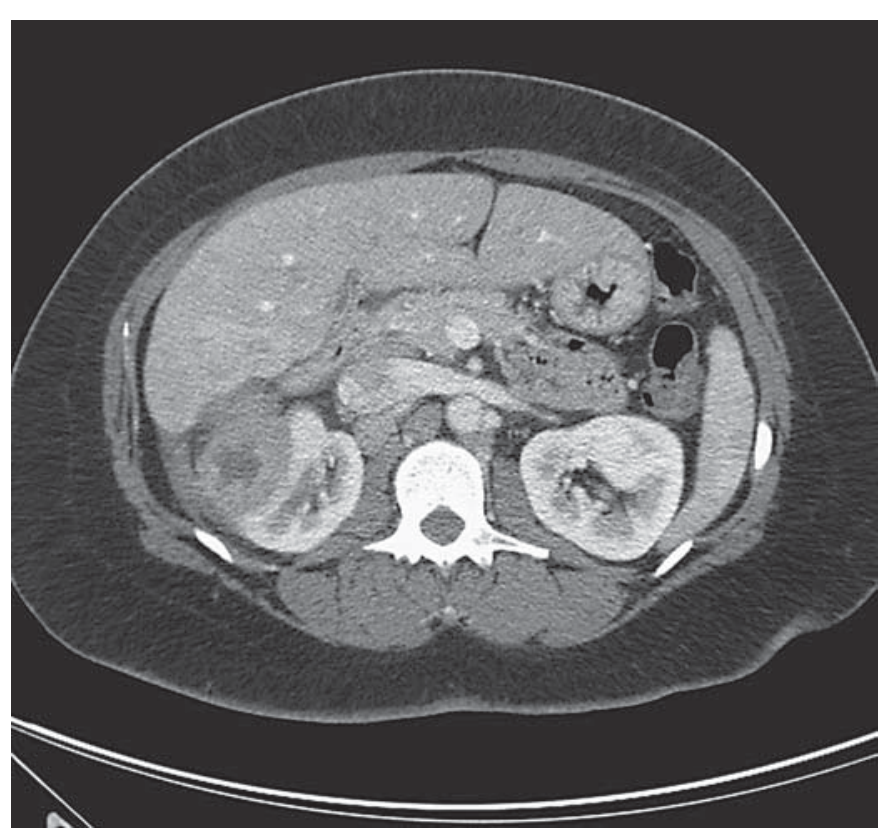

Fig. 1. CT scan of the mass showing a non-enhancing rim, central fluid density, and infiltration of the liver.

\section{KARGER}

Fax +41613061234 E-Mail karger@karger.ch www.karger.com
(C) 2006 S. Karger AG, Basel 0012-2823/06/0744-0236\$23.50/0

Accessible online at: www.karger.com/dig
Julian E. Losanoff, MD

Department of Surgery, Wayne State University 4160 John R, Suite 400, Detroit, MI 48201 (USA)

Tel. +1 313330 5659, Fax +1 31357610032

E-Mail jelosanoff@yahoo.com 
fat necrosis, or malnutrition; however, the exact mechanism remains unclear [2]. A review of the literature finds no other report of duodenal diverticulum involved in the process. The published incidence of duodenal diverticuli varies from 1 to $22 \%$ depending on the diagnostic methods; spontaneous perforation of a diverticulum is casuistic, with five published reports over the past 15 years [3]. The direct involvement of our patient's duodenal diverticulum by the XGP suggests that inflammation or perforation may have triggered the XGP. The published literature provides examples of communications found between XGP and a variety of anatomic structures including the colon [4, 5], stomach [6], bronchi [7], psoas muscles [8], and the abdominal wall where the severity of the process can vary and cause phlegmona [9], necrotizing fasciitis [10], or external fistulization $[11,12]$. The literature on XGP infiltrating the liver published so far describes more limited parenchymal engagement not requiring resection [13, 14]. Our recent experience reinforces that the organ involvement by XGP can be very extensive and potentially requires technically challenging multivisceral resection.

\section{References}

1 Khaira HS, Shah RB, Wolf JS: Laparoscopic and open surgical nephrectomy for xanthogranulomatous pyelonephritis. J Endourol 2005;19:813-817.

2 Chen HJ, Tsai JD, Lee HC, Chiu NC, Sheu JC, Shih SL, et al: Diffuse xanthogranulomatous pyelonephritis in a child with severe complications. Pediatr Nephrol 2004;19:14081412.

3 Miller G, Mueller C, Yim D, Macari M, Liang $\mathrm{H}$, Marcus S, et al: Perforated duodenal diverticulitis: a report of three cases. Dig Surg 2005;22:198-202.

4 Hortling N, Layer G, Albers P, Schild HH: Xanthogranulomatous pyelonephritis with septic lung metastases and infiltration of the colon (in German). Aktuelle Radiol 1997;7: 317-320.

5 Farina Perez LA, Pesqueira Santiago D, Alvarez Alvarez C, Zungri Telo ER: Diffuse xanthogranulomatous pyelonephritis with a renocolic fistula neglected for more than two years. Actas Urol Esp 2004;28:553-555.

6 Cline KL, Lang EK: Renal gastric fistula caused by staghorn calculus. J Urol 2005;174: 1107.

7 De Souza JR, Rosa JA, Barbosa NCB: Nephrobronchial fistula secondary to xanthogranulomatous pyelonephritis. Int Braz J Urol 2003;29:241-242.

8 Alan C, Ataus S, Tunc B: Xanthogranulomatous pyelonephritis with psoas abscess: two cases and review of the literature. Int Urol Nephrol 2004;36:489-493.
9 Ingenabel F: Xanthogranulomatous pyelonephritis with phlegmonous abdominal wall infiltration (in German). Dtsch Med Wochenschr 1995;120:816-817.

10 Ishigami K, Bolton-Smith JA, De Young BR, Barloon TJ: Necrotizing fasciitis caused by xanthogranulomatous and emphysematous pyelonephritis: importance of the inferior lumbar triangle pathway. Am J Roentgenol 2004;183:1708-1710.

11 Sherman SC, Limkakeng A: Xanthogranulomatous pyelonephritis with a nephrocutaneous fistula. J Emerg Med 2005;29:337-338.

12 Kiris A, Kocakoc E, Poyraz AK, Dagli F, Boztosun Y: Xanthogranulomatous pyelonephritis with nephrocutaneous fistula and coexisting renal replacement lipomatosis. The report of a rare case. Clin Imaging 2005;29: 356-358.

13 Esposito G, Savanelli A, de Luca U, Iaccarino V, Tamburrini O, di Prisco B: Xanthogranulomatous pyelonephritis in childhood: report of an unusual case. Z Kinderchir 1987; 42:120-122.

14 Lin TP, Fu LS, Peng HC, Lee T, Chen JT, Chi CS: Intra-abdominal actinomycosis with hepatic pseudotumor and xanthogranulomatous pyelonephritis in a 6-year-old boy. Scand J Infect Dis 2001;33:551-553. 